\title{
Our energy alternatives
}

Earth, Water, Wind and Sun: Our Energy Alternatives. By D. S. Halacy Jr. Pp. 186. (Harper and Row: New York and London, 1978.) £4.95.

Too many commentaries on 'alternative energy' seem to assume that we have only just discovered the sun. What is needed is a sense of historical perspective. It is otherwise too easy to overlook the fact that many ingenious technologies to exploit ambient energy flows like wind and sunlight were developed decades, indeed centuries ago. The principles and even the engineering of such technologies are often better understood than those of sc-called 'conventional' energy technologies like offshore oil extraction or nuclear power. This historical perspective is one of several distinctive virtues displayed in D. S. Halacy's book, an outstanding example of an under-rated discipline and popular science writing at its best.

Even for a battle-weary reader casehardened by continual exposure to outpourings about 'alternative energy', Halacy's book has an exhilarating freshness, and is quite unexpectedly absorbing, partly because of the frequently unfamiliar and fascinating detail included and partly because of the writing itself. The book sustains the reader's interest without gimmicks or gee-whizzery, succumbing neither to the breathless flashiness prevalent in the $1950 \mathrm{~s}$ nor to the more recently fashionable monitory breast-beating and finger-pointing. Furthermore, Halacy reveals himself to be a virtuoso of the short sentence. His prose races along, delivering an astonishing quantity of information accurately and effortlessly, without a hint of condescension.

$\mathrm{He}$ sets the stage with an introductory chapter entitled "The Energy Crisis Is Real", or, as he puts it, "But first, the bad news." It would doubtless be possible to quarrel with the picture he paints, at least in some particulars. $\mathrm{He}$ is preoccupied almost entirely with energy supply, and discounts far too completely the opportunities for improved efficiency-for optimising the balance between ambient energy, fuel energy, energy conversion systems, and desired end-use objectives. However, he then moves on to devote chapters to geothermal energy, waterpower, tidal power, sea thermal energy, wind, biofuels, and solar energy; and in each case his survey is both crisply concise and impressively comprehensive. He discusses basic principles, pioneering projects, current plans, proposals and prospects for the future, salting the discussion with striking examples and vivid turns of phrase. You probably know about Palmer Putnam's huge windmill on Grandpa's Knob; but did you know about Georges Claude's sea thermal plant with the intake pipe one and one quarter miles long, off the Cuban coast? In 1927? Or consider this thought-provoking aside, on the theoretical limit to recovery of energy from the wind: "(Extracting all the energy would mean bringing all the wind to a dead stop, an interesting possibility.)".

Halacy also avoids a pitfall into which many of his compatriots topple.
Unlike them he does not seem to believe that energy issues stop at the three-mile limit around the US. On the contrary he draws his examples and his ideas from every corner of the globe, although activities in the US do tend to predominate.

The book also offers a wealth of pictorial accompaniment to the text, including some photos of considerable rarity value.

All told, in 186 pages Halacy has put together a book which can be recommended with enthusiasm as one of the best available introductions to "our energy alternatives". Even its upbeat final sentence is welcome: "It's our move-and the prospects are encouraging". The next time some official spokesman threatens you with freezing in the dark, introduce him to Halacy.

Walt Patterson is energy consultant to Friends of the Earth (London) Ltd.

\section{Ecology of freshwater macrophytes}

River Plants: The Macrophytic Vegetation of Watercourses. By S. M. Haslam. Pp, 396. (Cambridge University Press: Cambridge and London, 1978.) $£ 27.50$.

Agnes Arber published her outstanding book on water plants nearly 60 years ago. Apart from Fritz Gessner's Hydrobotanik, Dr Haslam's is the first dealing with these plants, and based on original research, to have appeared since then. A causal analysis of the distribution of river plants throughout Britain is attempted in terms of flow, substrate and nutrients. These findings are applied to downstream changes in habitat and species composition in whole rivers. This leads to a classification of the vegetation of streams on soft rocks, streams on hard rocks and, finally, of channels with little flow. A preliminary account follows of the vegetation of watercourses in eastern North America and the book concludes with five chapters on applied aspectsuses and hazards created by river plants, their management and their relationship to pollution.

The author clearly intends to interest and indeed educate non-botanists and particularly those engaged in water planning and management; there is an initial set of drawings of 'field' plants, and symbols are used in text, tables and river maps for the commonest species. Perhaps this explains the way degrees of correlation between nutrient and species distribution are presented (Tables $8.2,8.6$ ) and the grouping of all moss data as 'mosses'. The professional biologist or teacher may find it difficult to extract succinct information because of inevitable compression of data and, sometimes, insufficient distinction between generalisations based on these data and on subjective assessment. The book is very well produced, with good illustrations, pleasant lay-out and few errorsthe most serious being the omission of all data from Fig. 6.12. These minor faults only slightly mar an outstanding, single-handed contribution to river biology - the first classification in terms of their macrophytes of British (and some North American) watercourses. The book can confidently be recommended to all those interested in the ecology of freshwaters.

D. H. N. Spence

D. H. N. Spence is Professor and. Head of the Department of Botany at the University of St Andrews, UK. 